\title{
RELATO DE EXPERIÊNCIA DO USO DE METODOLOGIAS ATIVAS E RECURSOS TECNOLÓGICOS NO CURSO TÉCNICO EM AGRONEGÓCIO DO SENAR AR/SC
}

\author{
FLORIANÓPOLIS/SC JULHO/2018
}

\author{
Katia Simoni Agapito Zanela - SENAR AR/SC - katia@senar.com.br \\ Tipo: Relato de Experiência Inovadora (EI) \\ Categoria: Métodos e Tecnologias \\ Setor Educacional: EDUCAÇÃO MÉDIA E TECNOLÓGICA
}

\begin{abstract}
RESUMO
O presente artigo apresenta o resultado de uma experiência bem sucedida com a utilização de metodologias ativas e recursos tecnológicos em um encontro presencial do curso Técnico em Agronegócio do SENAR/SC, realizado no polo de Campo Alegre/SC. A pesquisa realizada teve como objetivo verificar, na visão do aluno, o uso de metodologias ativas e recursos tecnológicos no processo de ensino aprendizagem. Ambos se apresentaram como metodologias inovadoras na educação profissional e podem apresentar-se como suporte para novas práticas docentes frente ao ensino tradicional.
\end{abstract}

Palavras-chave: Metodologias ativas; Recursos tecnológicos; Ensino híbrido. 


\section{INTRODUÇÃO}

O avanço da tecnologia nos últimos anos vem desencadeando novas formas de atuar na educação formal. O dinamismo das relações e as mudanças na sociedade atual não permitem que a educação vivencie um modelo tradicional de aprendizagem. A necessidade de aperfeiçoamento, capacitação e as novas demandas que surgem no mercado de trabalho a todo o momento requerem um modelo de educação mais flexível, democrático e aberto a novas possibilidades. A Educação a distância vem ao encontro dessas necessidades como uma proposta acessível de levar o conhecimento a todos, encurtando distâncias.

Neste sentido, em 2014 o SENAR- Serviço Nacional de Aprendizagem Rural lançou o curso Técnico em Agronegócio, na modalidade semipresencial que passa a ser o primeiro da entidade na modalidade Educação Formal. A finalidade do curso é formar profissionais habilitados nos processos de Gestão do Agronegócio nos mais diferentes segmentos e cadeias produtivas, possibilitando aos alunos estarem aptos para atuar na gestão das propriedades rurais e como agentes de assistência técnica, extensão rural e pesquisa, além de trabalhar em agroindústrias ou estabelecimentos ligados ao Agronegócio.

A expectativa é que os egressos da educação profissional proposta pelo senar tenham uma visão empreendedora e estejam aptos a enfrentar com segurança um mercado cada vez mais complexo e repleto de tecnologias inovadoras.

Em Santa Catarina o curso foi implementado em 2015 em uma parceria do SENAR Administração Central com a Administração Regional e os Sindicatos Rurais. Inicialmente foram implantados três polos e hoje o Estado conta com dez polos de apoio presencial, distribuídos em todo o Estado. Por acontecer na modalidade semipresencial, ou seja, $80 \%$ do curso a distância e $20 \%$ presencial foram realizadas parcerias com os sindicatos dos produtores rurais que através de resolução aprovada no conselho administrativo do SENAR, credenciaram suas sedes junto ao MEC como Polos de apoio presencial da Rede e-Tec. As aulas presenciais acontecem quinzenalmente em todas as unidades curriculares do curso com a presença de tutores presenciais que realizam as aulas nos polos ou acompanham os alunos em visitas técnicas realizadas em propriedades rurais e agroindústrias.

Os recursos instrucionais do curso contam com apostilas, vídeo aula em DVD e o ambiente virtual de aprendizagem com o apoio de monitoria, tutores a distância e materiais complementares. A metodologia do curso faz com que o processo de 
aprendizagem seja dinâmico com atividades e avaliações no ambiente virtual, participação e interação em fóruns e chats e encontros presenciais onde os alunos realizam visitas técnicas e vivenciam na prática a teoria disponibilizada no material do curso.

O curso Técnico em Agronegócio é um marco na capacitação de profissionais ligados ao agronegócio e os resultados são muito promissores devido principalmente à sua modelagem que se caracteriza pelo ensino híbrido.

\section{REFERENCIAL TEÓRICO}

A Educação a Distância (EAD) é definida no Decreto ํo 5.622 como: modalidade educacional na qual a mediação didático-pedagógica nos processos de ensino e aprendizagem ocorre com a utilização de meios e tecnologias de informação e comunicação com estudantes e professores desenvolvendo atividades educativas em lugares ou tempos diversos. (BRASIL, 2005).

A EAD, ao utilizar recursos tecnológicos, apresenta características que podem contribuir para uma aprendizagem baseada na construção de conhecimento, já que as facilidades de interação via Internet permitem um tipo de educação que é muito difícil de ser realizado presencialmente. (VALENTE, 2014, p. 147).

No meio rural a Educação a distância vem cumprindo um importante papel em levar conhecimento ao homem do campo a qualquer tempo e em qualquer lugar através dos cursos de capacitação e aperfeiçoamento oferecidos na modalidade EAD. O modelo híbrido adotado pelo SENAR cumpre um importante papel na missão de aliar teoria e prática indo ao encontro do lema da Instituição "Aprender a fazer fazendo".

Segundo Moran:

\footnotetext{
A maior parte do tempo - na educação presencial e a distância - ensinamos com materiais e comunicações escritos, orais e audiovisuais, previamente selecionados ou elaborados. São extremamente importantes, mas a melhor forma de aprender é combinando equilibradamente atividades, desafios e informação contextualizada. Para aprender a dirigir um carro, não basta ler muito sobre esse tema; tem que experimentar, rodar com ele em diversas situações com supervisão, para depois poder assumir o comando do veículo sem riscos. (MORAN, 2015, p. 15).
}

Moran (2015) afirma que a mudança vem nas Instituições de ensino onde uma forma cada vez mais híbrida de ensinar vem tomando forma. Tomando como foco o maior desenvolvimento do aluno e a inserção de metodologias ativas nesse contexto. Para o autor, as metodologias ativas de aprendizagem "[...] são pontos de partida para prosseguir em processos mais avançados de reflexão, de integração cognitiva, de generalização, reelaboração de novas práticas”. (MORAN, 2015, p. 18). 
O conceito de Metodologias ativas é muito amplo e refere-se a uma série de estratégias de ensino como problematizações, aprendizagem por pares, jogos, estudos de casos, sala de aula invertida e muitos outros recursos que colocam o aluno no centro do processo de ensino aprendizagem e como sujeito na construção do conhecimento. Exigem do aluno autonomia, criticidade e uma busca constante do seu próprio aprendizado. Yamamoto (2014, p. 85) cita

Yamamoto (2014, p. 85) cita ainda o pensamento sustentado por pesquisadores como Freire, Charlot, Demo, Heron e Alheit, de que "o ato de aprender é intransferível, só o indivíduo pode fazê-lo e ninguém pode aprender por outro".

Este pensamento também é sustentado por pesquisadores como Freire, Demo, entre outros. Partindo deste princípio os alunos tornam-se protagonistas da sua aprendizagem em uma educação que apesar de acontecer na modalidade à distância, aproxima os alunos e colaboram na formação de profissionais mais dinâmicos e proativos.

O uso das Metodologias ativas pelo tutor presencial faz com que a sua atuação seja de mediador no processo de ensino aprendizagem. O Tutor deixa de repassar o conteúdo preparado previamente e passa a construir junto com o aluno que deixa de ser espectador, passando a agente ativo em todas as atividades propostas. Percebe-se que nenhum aluno fica à mercê do processo, mas todos de forma dinâmica e autêntica interagem entre si.

O uso destas novas estratégias dentro da educação profissional e tecnológica tem mostrado uma contribuição relevante na prática da aprendizagem contextualizada. Professores conhecem uma nova forma de ensinar e aprender dentro da sala de aula que contribui para fazer com que os alunos pensem, reformulem, façam, discutam e ensinem. Na prática qualquer atividade desenvolvida em sala de aula que leve o aluno a esse caminho pode ser considerada uma metodologia ativa.

Por que limitar-se a transmitir conhecimentos se os estudantes dispõem para isto, além da imprensa escrita, inventada há mais de 500 anos, outros meios de acesso às informações? Por que não privilegiar discussões em torno de temáticas levantadas junto aos alunos? "Por que não prestigiar a aquisição de mentes criativas $e$ inquiridoras, através de debates, de resoluções de problemas extraídos da própria realidade sócio-cultural" (BALZAN, 1999, p.178).

\section{PROCEDIMENTOS METODOLÓGICOS}

Trata-se de um relato de experiência com o uso de metodologias ativas e recursos tecnológicos nos encontros presenciais do Curso Técnico em Agronegócio do 
SENAR/SC no Polo de Campo Alegre, Turma 2017/2. Em um primeiro momento buscouse reconhecer o que são metodologias ativas, seus objetivos, qual o papel do aluno e do Tutor no uso desta metodologia em sala de aula. Decidiram-se quais metodologias e recursos tecnológicos utilizar e colocou-se em prática nas aulas. Após a aula foi enviado aos alunos um questionário para avaliar o uso das metodologias ativas e recursos tecnológicos utilizados durante as aulas.

A base de dados utilizada para pesquisa foi o googleforms, ferramenta do google para coleta e análise de dados, sendo enviado o questionário para os 32 alunos presentes.

O Tutor presencial na Unidade Curricular de Introdução ao Agronegócio elaborou o plano de aula de acordo com os objetivos a serem alcançados na unidade curricular utilizando metodologias ativas condizentes ao processo de ensino aprendizagem e que pudessem alcançar os objetivos propostos na disciplina.

\section{Segundo MORAN:}

\footnotetext{
"As metodologias precisam acompanhar os objetivos pretendidos. Se queremos que os alunos sejam proativos, precisamos adotar metodologias em que os alunos se envolvam em atividades cada vez mais complexas, em que tenham que tomar decisões e avaliar os resultados, com apoio de materiais relevantes. Se queremos que sejam criativos, eles precisam experimentar inúmeras novas possibilidades de mostrar sua iniciativa. " ( MORAN,2015.p.01).
}

A proposta é expor os alunos a uma participação ativa, centrada na realidade que estão inseridos. Os desafios bem planejados de encontro as atividades propostas contribuem para a formação de conceitos através das descobertas, da pesquisa, da curiosidade, do assumir pontos de vista diferentes, do caminhar do simples para o complexo. Baseado nestes conceitos o Tutor presencial planejou as aulas utilizando tecnologias e aplicativos já disponíveis no mercado e outras atividades que estimulam a criatividade e a participação dos alunos. Dentre as atividades desenvolvidas e recursos utilizados estão:

\section{Aurasma}

É o nome de uma ferramenta digital desenvolvida pela empresa Autonomy, do grupo Hewlet-Packard (HP), a tecnologia permite que uma imagem estática ganhe movimento com a utilização de um tablet ou smartphone sobre ela. Através deste aplicativo de realidade aumentada o Professor Tutor marcou na apostila e em material complementar, figuras em que o aluno ao posicionar o celular tem acesso a materiais complementares como vídeos, figuras tridimensionais ou novas informações sobre o assunto estudado. 


\section{Meetoo}

É um aplicativo para enquetes e mensagens em tempo real, em qualquer hora e lugar. A ferramenta permite a interatividade e o monitoramento instantâneo da aprendizagem. $O$ Tutor projetou na tela questionamentos, gráficos e os alunos responderam as atividades diretamente no celular. As respostas geraram um gráfico onde o professor pode verificar as questões em que os alunos apresentam maior dificuldade e atuar de forma pontual nas principais dificuldades da turma.

\section{Jogos Didáticos}

O jogo didático aplicado consistia em vários mapas identificando as propriedades rurais com áreas e problemas diferentes a serem resolvidos. A turma foi dividida em equipes $\mathrm{e}$ cada uma delas recebeu uma cartela com possíveis soluções para os problemas apresentados. As equipes reuniram-se na busca de soluções e depois apresentaram ao grupo suas áreas e as soluções decididas pelo grupo para cada dificuldade apresentada.

\section{Drone}

O uso do drone nas aulas práticas possibilita aos alunos conhecerem os vários recursos deste equipamento e um contato mais próximo com a Agricultura de precisão através do georreferenciamento e mapeamento de áreas agrícolas. Durante a visita técnica o Professor utilizou o drone e pode mostrar aos alunos o funcionamento e todos os recursos disponíveis fazendo o georreferenciamento da propriedade visitada.

\section{Óculos 3D (Realidade Virtual)}

A Realidade virtual é criada através de um sistema computacional que engana os sentidos do usuário por meio de um ambiente virtual.

A Realidade virtual apresentada aos alunos com os óculos digitais permitiu aos mesmos a imersão em ambientes simulados que mesmo sem a intervenção direta dos alunos proporcionaram vivenciar as teorias e conceitos trabalhados em sala.

\section{RESULTADOS}

A fim de apoiar a análise da pesquisa aplicou-se um questionário virtual onde os alunos responderam de forma anônima e voluntariamente. Os resultados da pesquisa obtidos 
com o uso de Metodologias Ativas e Recursos Tecnológicos na aula presencial da Unidade Curricular de Introdução ao Agronegócio, turma 2017/2, polo de Campo Alegre são considerados positivos, visto que é unânime a aprovação, sendo que ao serem questionados $100 \%$ dos alunos confirmaram que o uso de novos recursos durante as aulas facilita a aprendizagem. Observa-se também que ao responderem o questionário quanto a colaboração no uso destes recursos, $97 \%$ dos alunos concordam que o uso de tecnologias e novas metodologias contribuem para melhorar a aprendizagem, 57,6\% também afirmam que torna a aula mais agradável e 66,7\% que estimula o processo criativo. Quanto ao tipo de Metodologia Ativa e recurso tecnológico utilizado pelo Professor, $87,9 \%$ dos alunos acharam que todas contribuíram no processo de Ensino aprendizagem. No entanto, $75,8 \%$ dos alunos ainda acreditam que, com relação ao aprendizado, se a aula fosse expositiva 0 aprendizado poderia ter sido o mesmo demostrando que os alunos ainda acreditam no modelo de ensino tradicional. Esses e outros dados da pesquisa podem ser verificados na figura a seguir:

Figura 1- Resultado da pesquisa
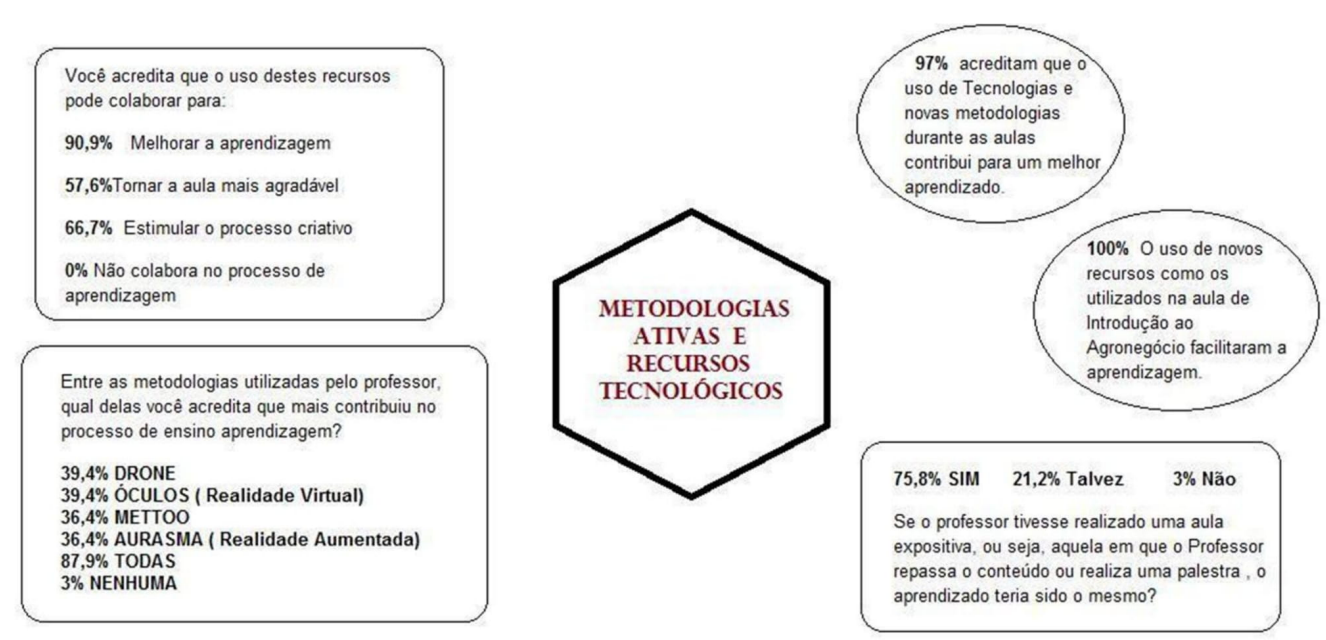

Fonte: Autoria Própria

\section{CONSIDERAÇÕES FINAIS}

É possível perceber durante a experiência piloto realizada em uma das turmas do Curso Técnico em Agronegócio, desenvolvido na modalidade semipresencial, a importância do 
uso de Metodologias Ativas e Recursos Tecnológicos no ensino híbrido proposto.

Salienta-se que os alunos ressaltaram a melhoria na aprendizagem e o estímulo do processo criativo na adoção das estratégias apresentadas. No entanto, uma boa parte dos alunos ainda acredita nas aulas expositivas e que o aprendizado poderia acontecer dentro do ensino tradicional, mas são unanimes em dizer que o uso de metodologias ativas e recursos tecnológicos facilitam e contribuem para uma melhor aprendizagem. Diante do exposto pode-se perceber como o uso de Metodologias ativas pode contribuir para a formação dos alunos e servir como referência de boas práticas para as outras turmas e a formação dos tutores presenciais. Os recursos tecnológicos apresentados aos alunos são fundamentais para a formação dos novos técnicos em agronegócio que atuarão nas mais diversas cadeias produtivas do Agronegócio se deparando com agricultura de precisão e modelos inovadores de produção e gestão.

A vivência da utilização de novos recursos em uma das turmas do Curso Técnico em Agronegócio do Senar Santa Catarina permite repensar as metodologias utilizadas durante as aulas presenciais e perceber como os recursos tecnológicos podem ser grandes aliados na formação profissional e tecnológica.

\section{REFERÊNCIAS}

BRASIL. Decreto no 5.622, de 19 de dezembro de 2005. Disponível em: <https://presrepublica.jusbrasil.com.br/legislacao/109743/decreto-5622-05>. Acesso em: 20 maio 2018.

BALZAN, N. C. Formação de professores para ensino superior: desafios e experiências. In: BICUDO, M. A. (Org). Formação do educador e avaliação educacional. São Paulo: Editora UNESP, p.173-188, 1999

MORAN, José Manuel. Mudando a educação com metodologias ativas.In: SOUZA,Carlos Alberto de; MORALES, Ofélia Elisa Torres (Org.). Convergências Midiáticas. educação e cidadania: aproximações jovens. Ponta Grossa. PR:UEPG/PROEX,2015. ( Coleções Mídias Contemporâneas, v. 2). p. 15-33. Disponível em: http://seer.ufs.br/index.php/edapeci/article/view/6509. Acesso em 20 Maio 2018.

VALENTE, José Armando. A comunicação e a educação baseada no uso das tecnologias de digitais de informação e comunicação. Revista Unifeso - Humanas e Sociais,v. $1, \quad$ n. $1, \quad$ p.141-166, 2014. Disponível em:https://seer.ufs.br/index.php/edapeci/article/view/6509 . Acesso em: 20 maio 2018 
YAMAMOTO, lara. Metodologias ativas de aprendizagem interferem no desempenho de estudantes. 2016. 101 f. Dissertação (Mestrado em Administração) — Universidade de São Paulo, São Paulo, $2016 . \quad$ Disponível em:http://www.teses.usp.br/teses/disponiveis/12/12139/tde-22092016-121953/pt-br.php. Acesso em: 20 maio 2018. 